\title{
Ecological and genetic relationships of the Forest-M form among chromosomal and molecular forms of the malaria vector Anopheles gambiae sensu stricto
}

Yoosook Lee*1, Anthony J Cornel2 ${ }^{2}$, Claudio R Meneses ${ }^{1}$, Abdrahamane Fofana ${ }^{3}$, Aurélie G Andrianarivo1, Rory D McAbee ${ }^{2}$, Etienne Fondjo ${ }^{4}$, Sekou F Traoré ${ }^{3}$ and Gregory C Lanzaro ${ }^{1}$

\begin{abstract}
Address: ${ }^{1}$ School of Veterinary Medicine, Department of Pathology, Microbiology and Immunology, University of California - Davis, Davis, CA, USA, ${ }^{2}$ Department of Entomology, University of California - Davis, Davis, CA, USA, ${ }^{3}$ Malaria Research and Training Center, Faculty of Medicine, University of Mali, Bamako, Mali and ${ }^{4}$ National Malaria Program, Ministry of Health, Yaoundé, Cameroon

Email: Yoosook Lee* - yoslee@ucdavis.edu; Anthony J Cornel - cornel@uckac.edu; Claudio R Meneses - crmeneses@ucdavis.edu; Abdrahamane Fofana - afofana@mrtcbko.org; Aurélie G Andrianarivo - agandriana@ucdavis.edu; Rory D McAbee - rdmcabee@uckac.edu; Etienne Fondjo - fondjoetienne@yahoo.fr; Sekou F Traoré - chieck@mrtcbko.org; Gregory C Lanzaro - gclanzaro@ucdavis.edu

* Corresponding author
\end{abstract}

Published: 21 April 2009

Malaria Journal 2009, 8:75 doi:10.1186/1475-2875-8-75

This article is available from: http://www.malariajournal.com/content/8///75

(C) 2009 Lee et al; licensee BioMed Central Ltd.

This is an Open Access article distributed under the terms of the Creative Commons Attribution License (http://creativecommons.org/licenses/by/2.0), which permits unrestricted use, distribution, and reproduction in any medium, provided the original work is properly cited.
Received: 30 December 2008

Accepted: 21 April 2009

\begin{abstract}
Background: Anopheles gambiae sensu stricto, one of the principal vectors of malaria, has been divided into two subspecific groups, known as the $M$ and $S$ molecular forms. Recent studies suggest that the $M$ form found in Cameroon is genetically distinct from the $M$ form found in Mali and elsewhere in West Africa, suggesting further subdivision within that form.
\end{abstract}

Methods: Chromosomal, microsatellite and geographic/ecological evidence are synthesized to identify sources of genetic polymorphism among chromosomal and molecular forms of the malaria vector Anopheles gambiae s.s.

Results: Cytogenetically the Forest $M$ form is characterized as carrying the standard chromosome arrangement for six major chromosomal inversions, namely $2 \mathrm{La}, 2 \mathrm{Rj}, 2 \mathrm{Rb}, 2 \mathrm{Rc}, 2 \mathrm{Rd}$, and $2 \mathrm{Ru}$. Bayesian clustering analysis based on molecular form and chromosome inversion polymorphisms as well as microsatellites describe the Forest $M$ form as a distinct population relative to the West African $M$ form (Mopti-M form) and the $S$ form. The Forest-M form was the most highly diverged of the An. gambiae s.s. groups based on microsatellite markers. The prevalence of the Forest $M$ form was highly correlated with precipitation, suggesting that this form prefers much wetter environments than the Mopti-M form.

Conclusion: Chromosome inversions, microsatellite allele frequencies and habitat preference all indicate that the Forest $M$ form of An. gambiae is genetically distinct from the other recognized forms within the taxon Anopheles gambiae sensu stricto. Since this study covers limited regions of Cameroon, the possibility of gene flow between the Forest-M form and Mopti-M form cannot be rejected. However, association studies of important phenotypes, such as insecticide resistance and refractoriness against malaria parasites, should take into consideration this complex population structure. 


\section{Background}

Anopheles gambiae sensu stricto is one of the major vectors responsible for malaria transmission in Africa. Genetic polymorphism in An. gambiae s.s. is a major factor contributing to the widespread occurrence of this disease vector both in time and space. Population genetic analysis of An. gambiae s.s. populations across Africa has revealed at least three genetically distinct groups within this single species[1]. However, an extensive literature describes a highly complex population genetic structure on a much smaller spatial scale in West and Central Africa [2-8].

Touré and his colleagues [5] examined the distribution of five paracentric chromosome inversions on the right arm of chromosome 2 (2R j, b, c, d and u). They established a convention for describing the karyotype of an individual mosquito, wherein a dash ('-') is used to designate the standard homozygote, ' 1 ' for a heterozygote and ' 2 ' for the inverted homozygote for each chromosome inversion. Each karyotype, thus, includes five characters, each character denoting the "genotype" for each of the five $2 \mathrm{R}$ chromosome regions that include the $\mathrm{j}, \mathrm{b}, \mathrm{c}, \mathrm{d}$ and $\mathrm{u}$ inversions. Analysis of karyotype frequencies among An. gambiae s.s. collected from a number of villages led to the identification of discrete subpopulations within this species which can be distinguished by their karyotype. These subpopulations were given non-Linnean designations and are collectively known as "chromosomal forms" $[2,5]$. Five chromosomal forms have been identified and named Mopti, Bamako, Bissau, Forest and Savanna according to the regions from which they were first collected, underscoring the association of each with a particular type of habitat. Various field-based studies clearly demonstrate that these forms show distinct patterns of seasonal and geographic distributions [2,5,6,9]. Detailed analysis of populations where multiple forms exist sympatrically revealed a high degree of reproductive isolation between the forms, with a strong preference for mating within rather than between forms [8].

Attempts to develop molecular diagnostics for the chromosomal forms culminated in the recognition of two distinct sequences in the intergenic spacer region of the ribosomal DNA locus [10,11]. A PCR-RFLP technique is now widely used to distinguish between individuals carrying one or the other of the ribosomal "alleles". These have been termed "molecular forms" of An. gambiae. There are two molecular forms, $\mathrm{M}$ and $\mathrm{S}$, which in some places (e.g. Mali) nearly always correspond with the chromosomal forms ( $\mathrm{S}=$ Savanna or Bamako Form, $\mathrm{M}=$ Mopti Form). In many places, however, the association between chromosomal form and molecular form appears to break down. For example in Senegal the Savanna chromosomal form is frequently of the $M$ molecular form $[12,13]$ and in Cameroon populations of the Forest chromosomal form may be either $M$ or S [14].
Analysis of gene flow between molecular forms has revealed that, as with the chromosomal forms, there is very strong positive assortative mating within molecular forms with little or no mating between forms $[8,14]$. Wondji et al. [14] found significant genetic differentiation between the $\mathrm{M}$ and $\mathrm{S}$ forms in Cameroon. The high levels of differentiation $\left(\mathrm{F}_{\mathrm{ST}}\right)$ they observed were uniformly distributed over ten microsatellite loci covering the entire genome, leading them to conclude that differentiation is the consequence of complete reproductive isolation between the $\mathrm{M}$ and $\mathrm{S}$ forms in Cameroon. Likewise Slotman et al. [15] reported significant genetic differentiation between the $\mathrm{M}$ and $\mathrm{S}$ forms in Cameroon. They also compared $M$ form populations in Cameroon with those in Mali and surprisingly found even higher levels of divergence than those reported between the $\mathrm{M}$ and $\mathrm{S}$ forms in both countries. These findings led them to conclude that there are two distinct $M$ forms, which they termed Mopti$M$ (described from Mali) and Forest- $M$ (described from Cameroon). These findings led to the hypothesis that both reproductive isolation, as determined by molecular form, and ecological factors affect the genetic makeup of An. gambiae s.s. and other markers such as chromosomal inversions should reflect such genetic divergence.

On the contrary, Yawson et al. [16] report a lack of differentiation between $M$ and $S$ forms in Ghana and Burkina Faso. They used both Bayesian clustering methods and $\mathrm{F}_{\mathrm{ST}}$-based analysis of allele frequencies at seven microsatellite loci. Although they did not find M/S hybrids, an admixture analysis suggests introgression between the two forms. They did, however, find strong differentiation between populations occupying different ecological zones, irrespective of $\mathrm{M}$ or $\mathrm{S}$ form, leading them to conclude that ecological barriers are more significant in restricting gene flow among populations than is reproductive isolation between the two forms.

In this paper, the results of a study investigating associations between chromosome inversions and molecular forms as well as the association between chromosome inversions and levels of precipitation are presented.

\section{Methods \\ Sample collection}

Adult females of An. gambiae s.s. were collected indoors using aspirators between 2002 and 2006 from the locations shown in Figure 1. Sample sizes range from 13 to 157 per site (Table 1). Mutengene is reported as Mutenguene and Pemperena as Pimperena in other publications. This paper followed the names listed in the worldwide index of cities and towns, Global Gazetteer version 2.1 (Falling Rain Genomics, Palo Alto, CA). Collections were made during the rainy season (collection dates are provided in Table 1). Ovaries were removed from semi-gravid females and stored in Carnoy's solution 


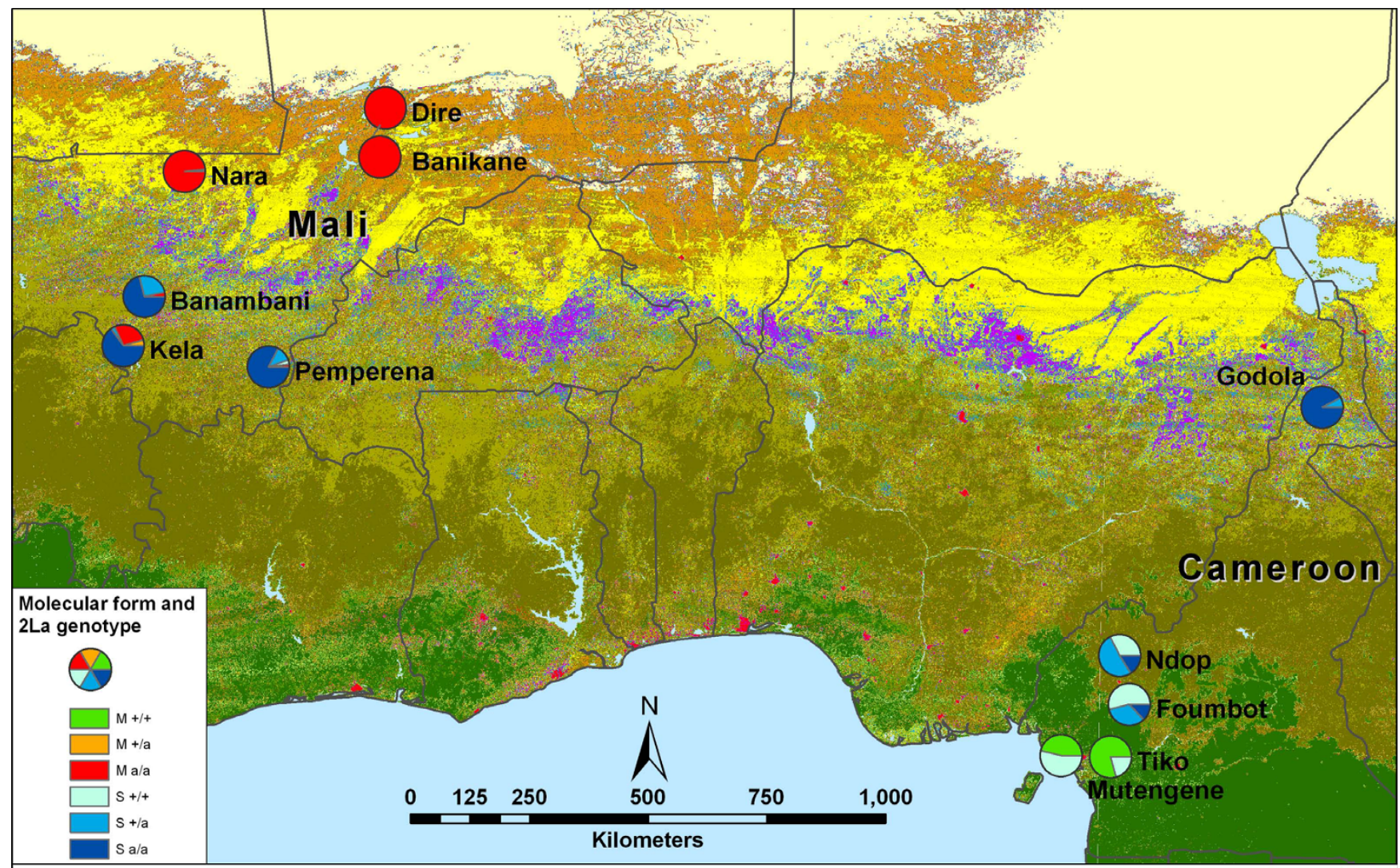

IGBP global vegetation classfication scheme

\begin{tabular}{|c|c|c|c|c|c|}
\hline o Water & 3 Deciduous needleleaf forest & 6 Closed shrublands & 9 Savannas & 12 Croplands & 15 Permanant snow and ice \\
\hline 1 Evergreen needleleaf forest & 4 Deciduous broadleaf forest & 7 Open shrublands & 10 Grasslands & 13 Urban and built-up & 16 Barren \\
\hline 2 Evergreen broadleaf forest & 5 Mixed forests & 8 Woody savannas & 11 Permanant wetlands & 14 Cropland/natural vegetation mosaic & Country outline \\
\hline
\end{tabular}

Figure I

Map of collection sites and genotype distributions. Relative proportion of molecular form and $2 \mathrm{La}$ chromosome inversion karyotypes for collection sites in Mali and Cameroon are shown in pie charts. Colours and corresponding land cover types for all 17 International Geosphere-Biosphere Programme (IGBP) global vegetation classes are shown in the legend at the bottom of the figure.

for cytogenetic analysis of polytene chromosomes [17]. Carcasses were stored in alcohol for subsequent DNA extraction. Genomic DNA was extracted using a DNeasy ${ }^{\otimes}$ extraction kit (Qiagen, Valencia, CA, USA).

\section{Species and molecular form diagnostic}

The PCR assay described by Scott et al. [18] was used to identify members of the An. gambiae species complex. Molecular forms within An. gambiae s.s. were identified based on published methods $[10,19]$.

\section{Cytogenetic analysis}

Polytene chromosomes were extracted from ovarian nurse cells using the protocol described by Hunt [17]. Chromosome banding patterns were examined using an Olympus BX-50 phase contrast microscope. Species identification and karyotype scoring were accomplished using the polytene chromosome map for the An. gambiae complex devel- oped by Coluzzi et al. [20] (maps available as supplement material). The chromosomal forms of An. gambiae s.s. were distinguished by scoring paracentric inversions on the right arm of chromosome 2, as described by Coluzzi et al. [9]. The genotypes of six chromosome inversions --2La, 2Rj, 2Rb, 2Rc, 2Rd, and $2 \mathrm{Ru}$--- were scored for each individual mosquito. Photographic images of chromosomes for the majority of individual mosquitoes used in this study are available on request.

\section{Microsatellite genotyping}

Twenty microsatellite loci located on the second and the third chromosome were screened, namely AG2H57, AG2H85, AG2H125, AG2H135, AG2H164, AG2H175, AG2H197, AG2H675, AG3H119, AG3H127, AG3H242, AG3H249, AG3H312, AG3H555, AG3H577, AG3H59, AG3H746, AG3H812, AG3H817, AG3H93 [21]. The same set of 12 markers on the third chromosome was 
Table I: Average precipitation in millimeters recorded near collection sites.

\begin{tabular}{|c|c|c|c|c|c|}
\hline \multicolumn{2}{|c|}{ site latitude } & \multirow[t]{2}{*}{ longitude } & \multirow{2}{*}{$\begin{array}{l}\text { Major IGBP land cover type within } \\
10 \mathrm{~km} \text { radius }\end{array}$} & \multirow{2}{*}{$\begin{array}{r}\text { Mean annual precipitation } \\
(\mathrm{mm} / \text { year })\end{array}$} & \multirow[t]{2}{*}{ Collection Date } \\
\hline Cameroon & & & & & \\
\hline Tiko & 4.0786 & 9.3681 & Evergreen broadleaf forests & $2789 \pm 1207$ & $\begin{array}{l}\text { Sep. } 2003 \\
\text { Aug. } 2006\end{array}$ \\
\hline Mutengene & 4.0994 & 9.3081 & Evergreen broadleaf forests & $2800 \pm 1240$ & Oct. 2003 \\
\hline Foumbot & 5.4851 & 10.6000 & Woody savannas & $1774 \pm 280.3$ & $\begin{array}{r}\text { Jul. } 2004 \\
\text { Aug. } 2006\end{array}$ \\
\hline Ndop & 6.0000 & 10.4167 & Woody savannas & $1749 \pm 271.0$ & Aug. 2004 \\
\hline Godola & 10.7000 & 14.2500 & $\begin{array}{c}\text { Mosaic of grasslands, permanent wetlands and } \\
\text { croplands }\end{array}$ & $826.8 \pm 256.6$ & Aug. 2005 \\
\hline \multicolumn{6}{|l|}{ Mali } \\
\hline Pemperena & 11.4670 & -5.7000 & Mosaic of woody savannas and savannas & $1004 \pm 133.2$ & Aug. 2002 \\
\hline Kela & 11.8870 & -8.4474 & Savannas & $958.5 \pm 105.0$ & Oct. 2006 \\
\hline Banambani & 12.8000 & -8.0500 & Savannas & $830.9 \pm 157.5$ & $\begin{array}{r}\text { Jul. } 2005 \\
\text { Aug. } 2006\end{array}$ \\
\hline Nara & 15.1630 & -7.2917 & Grasslands & $380.1 \pm 98.16$ & $\begin{array}{r}\text { Nov. } 2003 \\
\text { Jul. } 2005\end{array}$ \\
\hline Banikane & 16.0400 & -3.5900 & Open shrublands & $|4| .5 \pm 69.82$ & $\begin{array}{l}\text { Nov. } 2002 \\
\text { Oct. } 2003\end{array}$ \\
\hline Dire & 16.3670 & -3.4833 & Open shrublands & $170.8 \pm 72.77$ & Nov. 2002 \\
\hline
\end{tabular}

used in the previous study by Slotman et al. [15]. Some specimens used in Slotman et al. [15] that had associated karyotype data are also included in this study. Microsatellite markers were amplified using fluorescent primers and a PTC-225 thermolcycler (MJ Research, Watertown, MA). PCR products were mixed with a DS-30 Matrix Standard Kit (Dye Set D) (Applied Biosystems, Foster City, CA) and run on an ABI PRISM 3100 Genetic Analyzer. Electrophoretograms were analysed using ABI PRISM ${ }^{\circledast}$ GeneScan analysis software and Genotyper 3.7 NT.

\section{Environmental data}

Average annual precipitation for each collection site listed in Table 1 were computed using daily precipitation data, over multiple years, from weather stations within $15 \mathrm{~km}$ radius of each sample collection site. Daily precipitation recorded in Cameroon stations near mosquito collection sites was acquired by personal communication with Dr.
Yongkang Xue in the Department of Geography at the University of California - Los Angeles. Precipitation data for Mali stations were acquired by personal communication with Dr. Charles E. Taylor in the Department of Ecology and Evolutionary Biology at the University of California - Los Angeles. These data are provided in Additional file 1.

The International Geosphere-Biosphere Programme (IGBP) global vegetation classification scheme in $1 \mathrm{~km}$ resolution collected in 2004 was acquired in the form of the Land Cover Yearly L3 Global $1 \mathrm{~km}$ (MOD12Q1) data set produced by the NASA Moderate Resolution Imaging Spectroradiometer (MODIS) project $[22,23]$. The data is in Hierarchical Data Format (HDF), which is the standard data format for all NASA Earth Observing System (EOS) data products. The HEG version 2.9 (HDF-EOS to Geotiff) conversion tool was used to convert the acquired HDF file 
to Geotiff [24]. ArcMap version 9.1 was used to draw maps illustrating the habitat types surrounding each collection site.

\section{Statistics}

STRUCTURE software v2.2 [25-27] was used for Bayesian clustering analysis of seven markers which include genotypes of molecular form and of $2 \mathrm{La}, 2 \mathrm{Rj}, 2 \mathrm{Rb}, 2 \mathrm{Rc}, 2 \mathrm{Rd}$, and $2 \mathrm{Ru}$ chromosome inversions. Six consecutive symbols are used to describe karyotypes representing the genotype of inversions $2 \mathrm{La}, 2 \mathrm{Rj}, 2 \mathrm{Rb}, 2 \mathrm{Rc}, 2 \mathrm{Rd}$, and $2 \mathrm{Ru}$. '-' represents the standard (uninverted) homozygous arrangement, ' 1 ' heterozygotes, ' 2 ' inverted homozygotes. So, for example an individual that is homozygous for the inverted arrangement at 2La (2), homozygous standard for $2 \mathrm{Rj}(-)$, heterozygous for $2 \mathrm{Rb}(1)$, heterozygous for $2 \mathrm{Rc}$ (1), homozygous standard for 2Rd (-) and heterozygous for $2 \mathrm{Ru}$ (1) would be represented as: 2-11-1. Scoring of karyotypes that include inversions in the heterozygous condition is often ambiguous. For example, it is not possible to distinguish the $2 \mathrm{Rbcu} /+$ from $2 \mathrm{Rbc} / \mathrm{u}$ karyotype (i.e. gametic phase is uncertain). Regardless of gametic phase or haplotype, the input for this genotype is (-11-1, ----) or (-1---, --1-1). For this type of Bayesian analysis, either input represents exactly the same genotype so will have the same effect on the outcome of the clustering analysis. The Bayesian model does not distinguish the two but considers the fact that the corresponding individual is heterozygous for $2 \mathrm{Rb}, 2 \mathrm{Rc}$, and $2 \mathrm{Ru}$. Linkage between loci is something the model explores when it tries to find the most likely solution (grouping).

The same analyses were applied to microsatellite genotypes. Individuals were clustered into a hypothetical number of discrete populations, $K=[1,8]$ and the probability of the data given $K, \operatorname{Prob}(X \mid K)$, was computed for each run. Various combinations of burn-in period and sampling period were tested. In this case, a burn-in period of 100,000 and sampling period of 100,000 were sufficient. The probability of each individual belonging to each of the K populations was plotted using distruct software [28]. Raw data is provided in Table S1.

The ELB algorithm [29] as implemented in the Arlequin software package [30] was used to identify the gametic phase of karyotypes. A burn-in period of 10,000 and sampling period of 1,000 were used for estimating gametic phase. Estimated gametic phase information was subsequently used for a Hardy- Weinberg equilibrium (HWE) test. The Guo's Exact HWE Test [31] was performed both on the locus and gamete level for each collection, which consists of mosquitoes collected at the same site, same day, and of the same molecular form. A burn-in period of 100,000 and sampling period of 100,000 was used to calculate the probability of HWE. Arlequin was also used to calculate pair-wise $\mathrm{F}_{\mathrm{ST}}$ values based on microsatellite genotypes among the six groups identified in Bayesian clustering analysis. The neighbourjoining algorithm implemented in the neighbor program, a feature of Phylip v.3.67 [32,33] was used to illustrate relationships among groups. The drawtree program, also included in Phylip v.3.67, was used to generate a phylogenetic tree based on a pair-wise $\mathrm{F}_{\mathrm{ST}}$ distance matrix. $R$ software [34] was used for drawing boxplots, computing Wilcoxon rank sum tests, and performing linear regression.

\section{Results}

\section{Distribution of An. gambiae s.s. forms and inversions}

The distribution of molecular forms and 2La inversion genotypes (karyotypes) are illustrated in Figure 1. In Cameroon, $\mathrm{S}$ forms were found in all five sample locations, while $\mathrm{M}$ forms were localized in the evergreen broadleaf forest region below latitude $4.5^{\circ} \mathrm{N}$. In Mali, S forms were dominant below latitude $12^{\circ} \mathrm{N}$ in mostly savanna regions, while $\mathrm{M}$ forms were predominant above $15^{\circ} \mathrm{N}$ where land cover types are mostly grasslands or open shrublands (Table 1, Figure 1).

Chromosome inversion polymorphism was examined on the second chromosome, specifically $2 \mathrm{La}, 2 \mathrm{Rj}, 2 \mathrm{Rb}, 2 \mathrm{Rc}$, $2 \mathrm{Rd}$ and $2 \mathrm{Ru}$. Karyotypes, as well as molecular forms were distributed in a non-random fashion. For instance, only $25 \%$ of samples collected in Cameroon were 2La inversion homozytoes $(\mathrm{a} / \mathrm{a})$, mostly concentrated in a village called Godola located in northern Cameroon. The 2La inversion was completely absent in Tiko and Mutengene. In contrast, about $87 \%$ of specimens collected in Mali were 2La inversion homozygotes (Table 1, Figure 1) and only three specimens were 2La standard homozygotes $(+a /+a)$.

The $M$ forms found in Mali were polymorphic for all six inversions (96\% of the samples from Mali carried at least one copy of the $2 \mathrm{Rb}$ and/or c inversions), but were predominantly $2 \mathrm{La}$ inversion homozygotes. $\mathrm{M}$ form populations in Cameroon were predominantly fixed for the standard karyotype (M------) for all six inversions, including 2La. In the savanna region of northern Cameroon the $\mathrm{M}$ form occurred, but was rare (e.g. $1 \mathrm{M}$ form from Maroua, $10.60 \mathrm{~N} 14.33 \mathrm{E}, 3 \mathrm{M}$ forms from Ourodoukoudje, $9.083 \mathrm{~N} 13.683 \mathrm{E}$ and $4 \mathrm{M}$ forms from Raio, $9.117 \mathrm{~N}$ 13.717E). In these cases all had the M2-22-- (2La a/a, 2R bc/bc) karyotype. Due to very small sample size, these sites were not included in this study.

The $\mathrm{S}$ forms collected in Cameroon were polymorphic for the $2 \mathrm{La}$ and $2 \mathrm{Rb}$ inversions, although inversion homozygotes for $2 \mathrm{La}$ and $2 \mathrm{Rb}$ were relatively rare compared to Mali. In Cameroon, 30\% (43/143) of S forms were 2Rb homozygotes, but $93 \%$ of these were from a single site 
(Godola). The standard arrangement for $2 \mathrm{Rb}\left(+_{\mathrm{b}} /+_{\mathrm{b}}\right)$ was also common, occurring at a frequency of $45 \%(64 / 143)$ in Cameroon. Fewer $+_{b} / t_{b} S$ form individuals were observed in Mali $(18 \%, 48 / 273)$ than in Cameroon. S form $2 \mathrm{Rb}$ homozygotes occurred with equivalent frequencies in the villages of Banambani, Kela and Pemperena, perhaps because these occur in similar land cover types (Table 1). In drier areas of Mali such as grasslands and open shrublands, the $S$ form was rare. The correlation of $2 \mathrm{La}$ and $2 \mathrm{Rb}$ inversions with an environmental parameter, precipitation, is discussed below.

\section{Identification of discrete populations based on molecular form and karyotype}

Finding the most succinct classification of karyotypes was attempted by employing a Bayesian clustering analysis, the results of which are depicted in Figures 2 and 3. Each vertical line in Figure 2 represents a single mosquito and different colours represent different clusters. The length of each colour represents the membership coefficient for that individual for each corresponding population. The membership coefficient of an individual can be interpreted as the probability of belonging to a population, or how much of its genome originated from a population. Thus, if an individual is indicated mostly in one colour, that individual likely originated from the corresponding population. If an individual is represented in two colours of equal length, that individual has half of its genome originated from one population and the other half from another. The sum of the membership coefficients for each individual is 1 . Individuals were arranged such that the latitude of the collection sites increases from left to right on the bar plots in Figure 2. In some areas, the colours appear to be a solid block because the corresponding individuals have identical karyotypes. Karyotypes associated with each of the six populations are provided in Table 2. An additional character was added for molecular form. 'M', for $\mathrm{M}$ form, 'S', for $\mathrm{S}$ form.

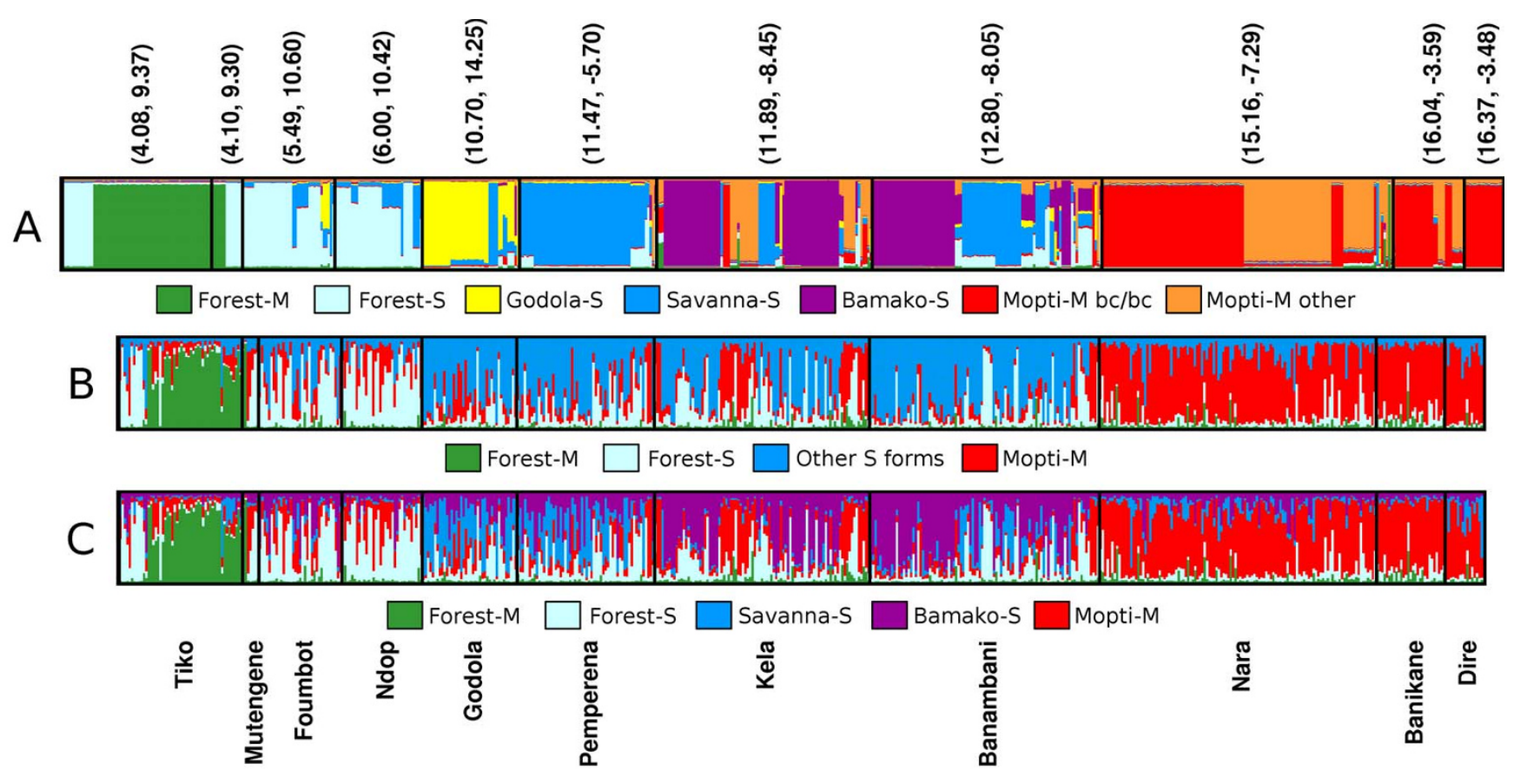

Figure 2

Structure clustering results. A: Membership coefficients of all individuals for $K=7$. Bayesian clustering based on seven markers, which include molecular form, the $2 \mathrm{La}, 2 \mathrm{Rj}, 2 \mathrm{Rb}, 2 \mathrm{Rc}, 2 \mathrm{Rd}$, and $2 \mathrm{Ru}$ inversions. Each vertical line represents a single individual. Different colours represent different clusters (= forms). The green colour corresponds to Forest-M form, light-blue to Forest-S form, yellow to Godola-S form, blue to Savanna-S form, purple to Bamako-S form, red to Mopti-M form bc/bc homozygotes, and orange to the "other" Mopti-M forms. Individuals are ordered such that the latitude of collection sites increase from left to right. The latitude and longitude of each collection site are indicated on top of the bar plots and the names of the collection sites are indicated below the bar plots. The associated karyotypes are summarized in Table 2. B: Membership coefficients for $\mathrm{K}=4$ clustering based on microsatellite markers. The green colour corresponds to Forest-M form, light-blue to Forest-S form, Blue to all other S forms, and red for Mopti- M form. Note that separation of Godola-S, Savanna-S and Bamako-S were not supported at $K=4$. C: Membership coefficient for $K=5$ clustering based on microsatellite markers. The color scheme is similar to Figure $3 \mathrm{~B}$, with the addition of the Bamako-S form indicated in purple. 

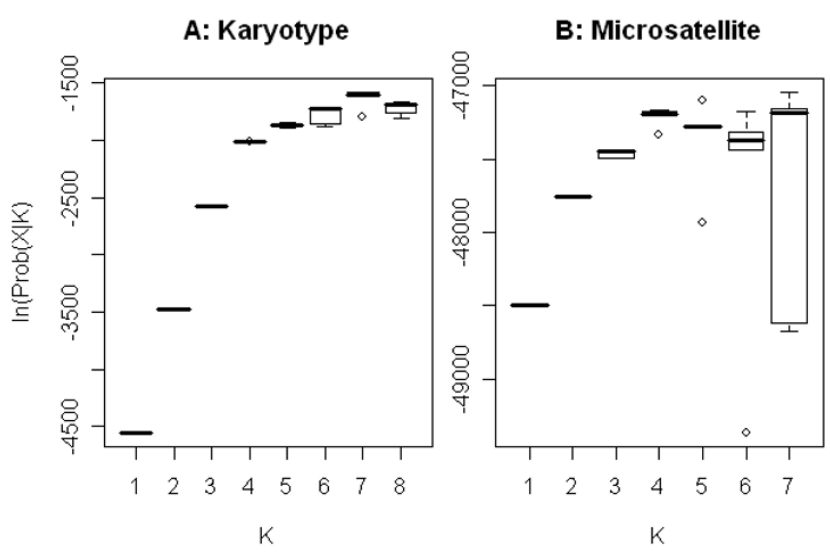

Figure 3

Posterior probabilities of karyotype and microsatellite based Bayesian cluster analyses. The boxplots were drawn after collecting posterior probabilities of 5 independent runs. The medians were drawn as thick black lines. Some boxes appear as a single line because the range of the posterior probabilities is too narrow to show as a box. Outliers are shown as open circle $(\mathrm{m})$. A: Clustering of individuals into seven groups $(K=7)$ was the most probable solution for molecular form and karyotype data. B: Analysis of clustering of genotypes at 20 microsatellite loci yielded several outcomes with relatively high likelihood. Liklihoods for $\mathrm{K}=4, \mathrm{~K}$ $=5$ and $\mathrm{K}=7$ are similarly distributed (Wilcox twosample test, $P>.05)$.

The analyses depicted in Figures 2A and 3A included molecular form and six chromosome inversion genotypes as criteria. A range of values for $\mathrm{K}$ was tested, which denotes the hypothetical number of populations. The solutions for $\mathrm{K}=7$ have the highest likelihood (Figure $3 \mathrm{~A})$.

The Forest $\mathrm{M}$ form was classified as a discrete population, fixed for the standard arrangement (M-----) for all six inversions and carrying the $\mathrm{M}$ ribosomal allele (Table 2, shown in green in Figure 2). These are the same individuals identified as 'M 2L+/+' in Figure 1 (marked in green) mostly found in evergreen broadleaf forest regions in Cameroon. The observed lack of inversion polymorphism is consistent with previous observations by Wondji et al. $[14,35]$. Although some inversion polymorphism in $M$ forms was observed in their study these were restricted to woody savanna areas (Tibati, Dschang) or to habitats at the border of evergreen forests and woody savannas. Two $\mathrm{M}$ form samples from Mali (one from Kela and the other from Banikane) had standard 2R arrangements. However, both were homozygous for $2 \mathrm{La}(2 \mathrm{La}$ a/a), consequently the Bayesian models predicted that these two samples belong to the Mopti-M form group rather than Forest $\mathrm{M}$ form (See Additional file 2 for genotype and corresponding membership coefficients).
The Bayseian analysis based on molecular form and karyotype (Figure 2A) divided the Mopti chromosomal form into two groups: Mopti-M bc/bc (red) and Mopti-M "other" (orange). Significant deviation from Hardy-Weinberg equilibrium (HWE) was observed among $M$ form populations at Nara $(\mathrm{P}=0.0000 \pm 0.0000)$ and Banikane $(\mathrm{P}=0.00016 \pm 0.00004)$. (Note that the $\mathrm{M}$ form population at Dire was excluded from HWE analysis because it is monomorphic for the bc karyotype (M2-22--; bc/bc)). The authors suspect that separation of the Mopti-M form reflects strong selection for the $2 \mathrm{Rbc}$ inversion in response to the arid conditions that exist at these sites. This observation is consistent with results reported by Touré et al. [3] who observed an increase in the frequency of $2 \mathrm{Rb}$ in $\mathrm{M}$ forms as precipitation decreases. However, this trend is not limited to $\mathrm{M}$ forms and a similar trend was also found in S forms (See Additional file 3). Overall, 2Rb inversion frequencies increased as precipitation decreases (Figure 4B)[5].

The $S$ molecular form was divided into four groups, Forest-S (light blue), Savanna-S (blue), Bamako-S (purple), and Godola-S (yellow, Figure 2A). Forest-S forms were polymorphic for the $2 \mathrm{La}$ and $2 \mathrm{Rb}$ inversions, although inversion homozygotes for $2 \mathrm{La}$ or $2 \mathrm{Rb}$ were absent (Table 2 ). In contrast, inversion homozygotes for $2 \mathrm{La}$ and $2 \mathrm{Rb}$ were very common in the Savanna-S form (Table 2). The amount of gene flow between these two groups was relatively high as indicated by the presence of many individuals with mixed light blue and blue colors. This could be interpreted as active gene flow between the two groups, or less confidence in the clustering due to a lack of more discriminatory markers and/or the groups having relatively similar inversion frequencies.

Individuals homozygous for $2 \mathrm{Rj}, \mathrm{c}$, and $\mathrm{u}$ inversions were classified as the Bamako-S group (shown in purple in Figure 2A); this group represents the Bamako chromosomal form $[5,9]$. The $2 \mathrm{Rb}$ inversion was polymorphic within this group. Deviation from HWE were significant among $S$ forms collected in Kela $(P=0.0000 \pm 0.0000)$ and Banambani ( $P=0.0000 \pm 0.0000)$ as expected considering the $\mathrm{S}$ forms in these locations include both Bamako and Savanna chromosomal forms.

The samples collected in Godola were all of the S molecular form, but included unusual karyotypes that do not fit within the conventional definitions for An. gambiae chromosomal forms $[5,9,36]$. The Savanna form typically has the $2 \mathrm{Rb}$ inversion alone or in combination with the $2 \mathrm{Rc}$ and $\mathrm{u}$ inversions. At Godola, with the exception of a single individual, the $2 \mathrm{Ru}$ inversion was absent. The most common arrangement ( $82 \%$ of individuals) was $2 \mathrm{Rbcd}$ and $40 \%$ of the individuals sampled from this site were homozygous for the $2 \mathrm{Rb}, \mathrm{c}$ and $\mathrm{d}$ inversions (Table 2). 
Table 2: Sample table site names, locations, sample sizes and molecular form and 2 La inversion composition

\begin{tabular}{|c|c|c|c|c|c|c|c|c|}
\hline \multirow[b]{2}{*}{ site $\mathbf{N}$} & & \multicolumn{6}{|c|}{ Molecular form \& 2La karyotype } & \multirow[b]{2}{*}{ M/S hybrid } \\
\hline & & $M+/+$ & $M+/ a$ & $M a / a$ & $\mathrm{~S}+1+$ & $\mathbf{S}+/ \mathbf{a}$ & $\mathbf{S} \mathbf{a} / \mathbf{a}$ & \\
\hline \multicolumn{9}{|c|}{ CAMEROON } \\
\hline Tiko & 63 & 50 & 0 & 0 & 13 & 0 & 0 & 0 \\
\hline Mutengene & 13 & 6 & 0 & 0 & 7 & 0 & 0 & 0 \\
\hline Foumbot & 39 & 0 & 0 & 0 & 21 & 13 & 5 & 0 \\
\hline Ndop & 37 & 0 & 0 & 0 & 12 & 19 & 6 & 0 \\
\hline Godola & 40 & 0 & 0 & 0 & 0 & 3 & 37 & 0 \\
\hline \multicolumn{9}{|l|}{ MALI } \\
\hline Pemperena & 58 & 0 & 0 & 1 & 2 & 7 & 48 & 0 \\
\hline Kela & 91 & 0 & 4 & 25 & 0 & 3 & 59 & 0 \\
\hline Banambani & 96 & 0 & 0 & 3 & 0 & 25 & 68 & 0 \\
\hline Nara & 117 & 1 & 2 & 113 & 0 & 0 & 1 & 0 \\
\hline Banikane & 25 & 0 & 0 & 25 & 0 & 0 & 0 & 0 \\
\hline Dire & 16 & 0 & 0 & 16 & 0 & 0 & 0 & 0 \\
\hline Total & 595 & 57 & 6 & 183 & 55 & 70 & 224 & 0 \\
\hline
\end{tabular}

$\mathrm{N}=$ Total number of An. gambiae samples for each collection site. $M=M$ molecular form, $\mathrm{S}=\mathrm{S}$ molecular form, '+' stands for standard arrangement for 2 La inversion, 'a' for inverted arrangement, and '?' for unknown arrangement.

Deviation from HWE in the S-Godola population was significant $(\mathrm{P}=0.0064 \pm 0.0002)$, mainly due to 1 specimen with the S2-22-2 (bcu/bcu) genotype. Only six individuals $(13 \%)$ had typical Savanna karyotypes. The $2 \mathrm{Rd}$ inversion is a very unusual arrangement both in Mali (freq. $=0.008$ ) and Cameroon (freq. at sites other than Godola $=0.026$ ). In Godola the 2Rd inversion occurred at a frequency of 0.544 . Moreover, $S$ form individuals carrying the $2 \mathrm{Rbc}$ combination (without $2 \mathrm{Ru}$ ), typical arrangements for the Mopti chromosomal form ( $\mathrm{M}$ molecular form), is noteworthy.

\section{Identification of discrete populations based on microsatellite genotypes}

Genetic differentiation between identified groups was estimated using pair-wise $\mathrm{F}_{\mathrm{ST}}$ values based on 20 microsatellite markers on the second and third chromosomes. Results from this analysis indicate that the Forest-M group (M-----) is the most genetically distant from all other groups. This result was consistent with the previous study by Slotman et al. [15]. The matrix of genetic distances is provided in Table 3 . An unrooted tree calculated from the distance matrix using a neighbour-joining algorithm is provided in Figure 4. Genetic differentiation was low between the Mopti-M 2R bc/bc group and the "other" Mopti- $\mathrm{M}$ form $\left(\mathrm{F}_{\mathrm{ST}}=0.0029, \mathrm{P}=0.016\right)$. Notice that genetic differentiation between the Savanna-S and Bamako-S groups were the smallest among the four $S$ molecular form groups but still highly significant $\left(\mathrm{F}_{\mathrm{ST}}=\right.$ $0.0056, P=0.0000)$. These two forms are thought to mate assortatively and are considered to represent incipient species [5,37].

The outcome of the Bayesian clustering analysis was compared based on karyotypes with those based on microsatellite genotypes (Figures 2B, C and 3B). Wilcox twosample test indicates that $K=4$ and $K=5$ have similar likelihoods $(P=0.42) . K=5$ generated a solution with the highest posterior probability $\operatorname{Prob}(\mathrm{X} \mid \mathrm{K})$, where $\mathrm{X}$ is genotype data. Boxplots drawn after collecting posterior prob- 


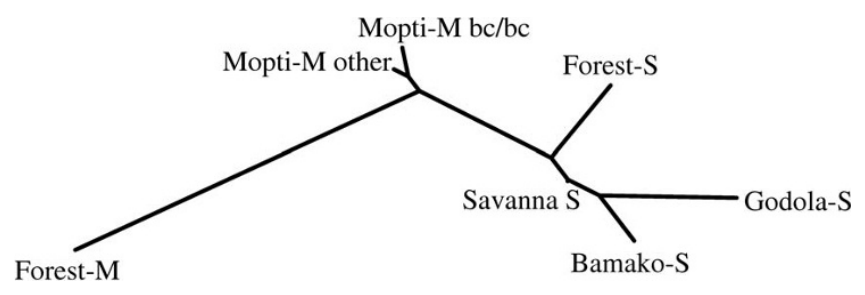

Figure 4

Unrooted phylogenetic tree (neighbour joining) of the seven groups of An. Gambiae identified by Bayesian analysis (using Structure software), as illustrated in Figure 2A. Tree is based on pair-wise $\mathrm{F}_{\mathrm{ST}}$ values derived from allele frequencies at 20 microsatellite loci on chromosomes 2 and 3. Distances between all branches are significant (see Table 3).

abilities from 5 independent runs are presented in Figure $3 \mathrm{~B}$ and resulting membership coefficients are plotted in Figure $2 B(K=4)$ and $2 C(K=5)$.

Under the assumption of $\mathrm{K}=5$ (Figure 2C), the Bayesian model identified the Forest- $M$ form group (green) in Tiko and Mutengene, a Forest-S form (light blue) group, mostly concentrated in southern and central Cameroon, Bamako-S form group, Savanna-S group, and the Mopti$\mathrm{M}$ form (red) group in Mali. The Savanna-S form group indicated in blue subsumes the Godola-S group identified based on karyotype (Figure 2A). Unlike karyotype clustering, the Mopti-M form remained as a single group based on microsatellite genotypes at both $\mathrm{K}=4$ and $\mathrm{K}=5$. This is reflected in the relatively low $\mathrm{F}_{\mathrm{ST}}$ values between the two groups (Table 3, Figure 4 ).

\section{Chromosome inversions, molecular forms and the environment}

As latitude increases in Cameroon the proportion of $\mathrm{M}$ form decreases whereas the inverse correlation was found in Mali. Generally, precipitation is higher at lower lati- tudes both in Mali and Cameroon (Table 4), but the amount of precipitation in southern Cameroon is 2-3 times higher than that in southern Mali. Average precipitation per collection site is summarized in Table 4 (detailed data are provided in Table S2). The correlation between the proportion of $\mathrm{M}$ molecular forms and annual precipitation in Cameroon and Mali is illustrated in Figure 5. The proportion of $\mathrm{M}$ form increases as precipitation increases in Cameroon $(\mathrm{P}=0.00012)$. In contrast, the proportion of $\mathrm{M}$ form decreases as precipitation increases in Mali $\left(\mathrm{P}<2 \times 10^{-16}\right)$. The dramatic difference in environmental preference between the Forest- $M$ (Cameroon) and Mopti-M (Mali) is reflected in the genetic distance between the two illustrated in Table 3, Figure 4 and as described earlier by Slotman et al. [15].

The International Geosphere-Biosphere Programme (IGBP) land cover scheme (Figure 1) identifies Tiko and Mutengene, where the Forest-M form is abundant, as an evergreen broadleaf forest region. On the other hand, the Mopti-M form is collected in the much drier savanna (Kela, Banambani), grassland (Nara), or open shrubland habitats (Dire, Banikane).

The correlation between the 2La inversion frequency and annual precipitation is shown in Figure 6A. The frequency of the $2 \mathrm{La}$ inversion decreased as the amount of precipitation increased $\left(\mathrm{P}<2 \times 10^{-16}\right)$; a pattern consistent with previous studies in Africa [2,38]. As previously described, much fewer S form 2La homozygotes were observed in Cameroon and most of these were concentrated in Godola. All the study sites in Mali were much drier than those in Cameroon, except for Godola. This is reflected in the abundance of the 2La inversion in samples collected in Mali. Northern sites such as Nara and Banikane, located near the Sahara Desert, are particularly dry and the Mopti chromosomal form prevails at these sites. Some $2 \mathrm{R}$ standard arrangement were found in Mali, but all of them, except one, were 2La inversion homozygotes (M2-----);

Table 3: Major karyotypes associated with each population identified in Bayesian clustering analyses.

\begin{tabular}{|c|c|c|c|c|c|c|c|}
\hline \multirow{2}{*}{$\begin{array}{c}\begin{array}{c}\text { Clustering based on microsatellite } \\
\text { genotype }(\mathrm{K}=5)\end{array} \\
\text { Clustering based on karyotype }(\mathrm{K}=7)\end{array}$} & \multirow{2}{*}{$\begin{array}{l}\text { Forest-M } \\
\text { Forest-M }\end{array}$} & \multirow{2}{*}{$\begin{array}{l}\text { Forest-S } \\
\text { Forest-S }\end{array}$} & \multicolumn{2}{|c|}{ Savanna-S } & \multirow{2}{*}{$\begin{array}{l}\text { Bamako-S } \\
\text { Bamako-S }\end{array}$} & \multicolumn{2}{|c|}{ Mopti-M } \\
\hline & & & Godola-S & Savanna-S & & Mopti-M bc/bc & Mopti-M other \\
\hline Color (Figure 2) & Green & Light blue & Yellow & Blue & Purple & Red & Orange \\
\hline Molecular form & $M$ & S & $\mathrm{S}$ & $S$ & S & $M$ & $M$ \\
\hline \multirow[t]{4}{*}{ Karyotypes } & & S -----(42) & S2-21I-(15) & S2-2---(78) & S22I 2-2(52) & & M2-II-I(50) \\
\hline & M------(57) & SI-I---(2I) & S2-222-(I2) & SI-2---(27) & $S 22-2-2(39)$ & M2-22--(I45) & M2-II--(39) \\
\hline & & SI----(17) & S2-III-(3) & S2-I---(20) & $S 2222-2(15)$ & & $M 2-21--(6)$ \\
\hline & & S--I---(12) & & & & & M2-----(2) \\
\hline
\end{tabular}

The six consecutive symbols describing karyotypes represent the genotype of $2 \mathrm{La}, 2 \mathrm{Rj}, 2 \mathrm{Rb}, 2 \mathrm{Rc}$, $2 \mathrm{Rd}$, and $2 \mathrm{Ru}$ listed in order. '-' represents standard (uninverted) homozygous arrangement, 'I' heterozygote, ' 2 ' inverted homozygote. 


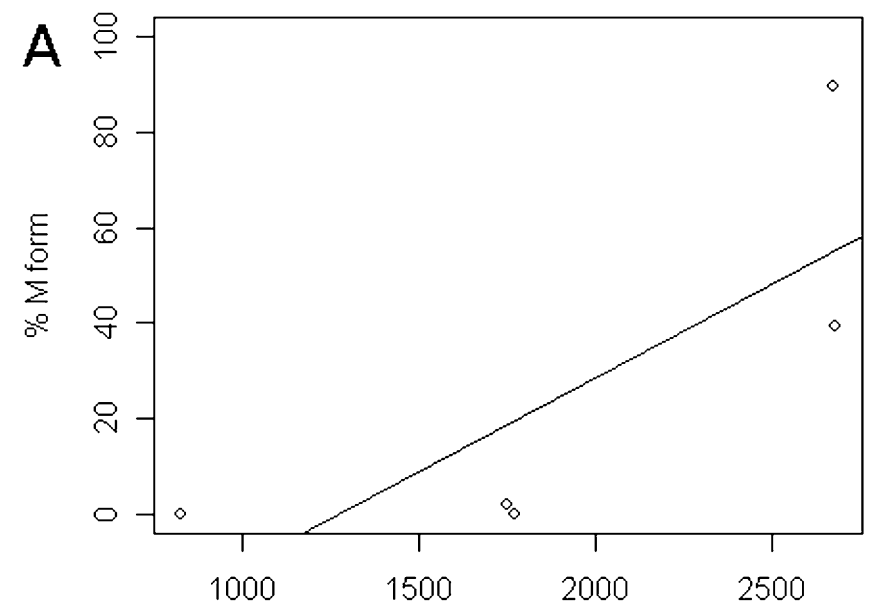

Average annual precipitation (mm)

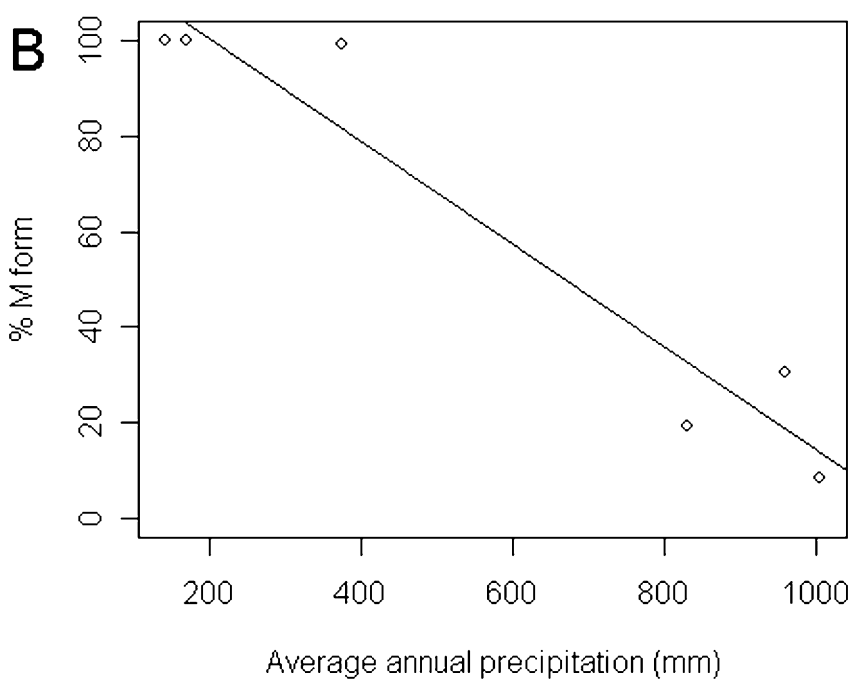

\section{Figure 5}

Precipitation and molecular form. Correlation between the proportion of $M$ molecular forms and the average annual precipitation in (A) Cameroon and (B) Mali. Average annual precipitation was calculated using annual precipitation at multiple weather stations at or near collection sites (within a $15 \mathrm{~km}$ radius) and over multiple years. $\mathrm{m}=$ average annual precipitation at each site. Details of precipitation data are provided in Table S2. A. The proportion of the M forms increases as precipitation increases in Cameroon. B. The opposite trend was observed in Mali. These seemingly conflicting results illustrate that the Forest-M form and Mopti-M form differ with respect to habitat preference as well as being differentiated genetically. The solid line is a linear model $(y \sim a x+b)$ of the data. $(A)$ For the Cameroon data, $a=0.0395 \pm 0.0184(P=0.121)$ and $b=-50.5 \pm 37.8(P=$ $0.274)$. (B) For the Mali data, $a=-0.108 \pm 0.0150(P=0.00197)$ and $b=122 \pm 10.3(P=0.000283)$.

these were classified as the "other Mopti-M" group (orange in Figure 2A). The simple presence of the 2La inversion in $\mathrm{M}$ forms was sufficient to distinguish Forest$M$ from Mopti-M form in this case.

A similar trend was observed for the $2 \mathrm{Rb}$ inversion. The frequency of $2 \mathrm{Rb}$ increased as precipitation decreased, as reported by Coluzzi et al. [2]. Individuals homozygous for $2 \mathrm{Rb}(\mathrm{b} / \mathrm{b})$ and $2 \mathrm{La}(\mathrm{a} / \mathrm{a})$ had a high probability of being classified in the Savanna-S group rather than Forest-S group. Because of the inverse correlation between $2 \mathrm{Rb}$ and precipitation, division between the Forest-S group and Savanna-S or Godola-S groups is likely due to the skewed $2 \mathrm{Rb}$ frequency.

Clustering results based on microsatellite genotypes indicates that the Godola-S forms are relatively close to the Savanna-S and Bamako-S forms (Figure 2B and 2C, and

Table 4: Estimation of pair-wise genetic divergence $\left(F_{S T}\right)$.

\begin{tabular}{|c|c|c|c|c|c|c|c|}
\hline Label & Population & 1 & 2 & 3 & 4 & 5 & 6 \\
\hline I & Forest $M$ & - & & & & & \\
\hline 2 & Forest $\mathrm{S}$ & $0.04263 * * *$ & - & & & & \\
\hline 3 & Godola S & $0.04260^{* * *}$ & $0.02077^{* * *}$ & - & & & \\
\hline 4 & Savanna S & $0.03410 * * *$ & $0.00733^{* * * *}$ & $0.01126^{* * * *}$ & - & & \\
\hline 5 & Bamako S & $0.04055^{* * *}$ & $0.01183^{* * * *}$ & $0.01224 * * *$ & $0.00559 * * *$ & - & \\
\hline 6 & Mopti M other & $0.02487 * * *$ & $0.01282^{* * *}$ & $0.0235 I^{* * * * *}$ & $0.01469 * * *$ & $0.02328 * * *$ & - \\
\hline 7 & Mopti-M bc/bc & $0.02794 * * *$ & $0.01534 * * *$ & $0.02095 * * *$ & $0.01581 * * *$ & $0.02333 * * *$ & $0.00288^{*}$ \\
\hline
\end{tabular}

Pair-wise $\mathrm{F}_{\mathrm{ST}}$ distance calculated based on 20 microsatellite loci among groups identified in the Bayesian clustering analysis $(K=7)$. $* P<0.05$, $* * p<0.01$, *** $p<0.001$. 

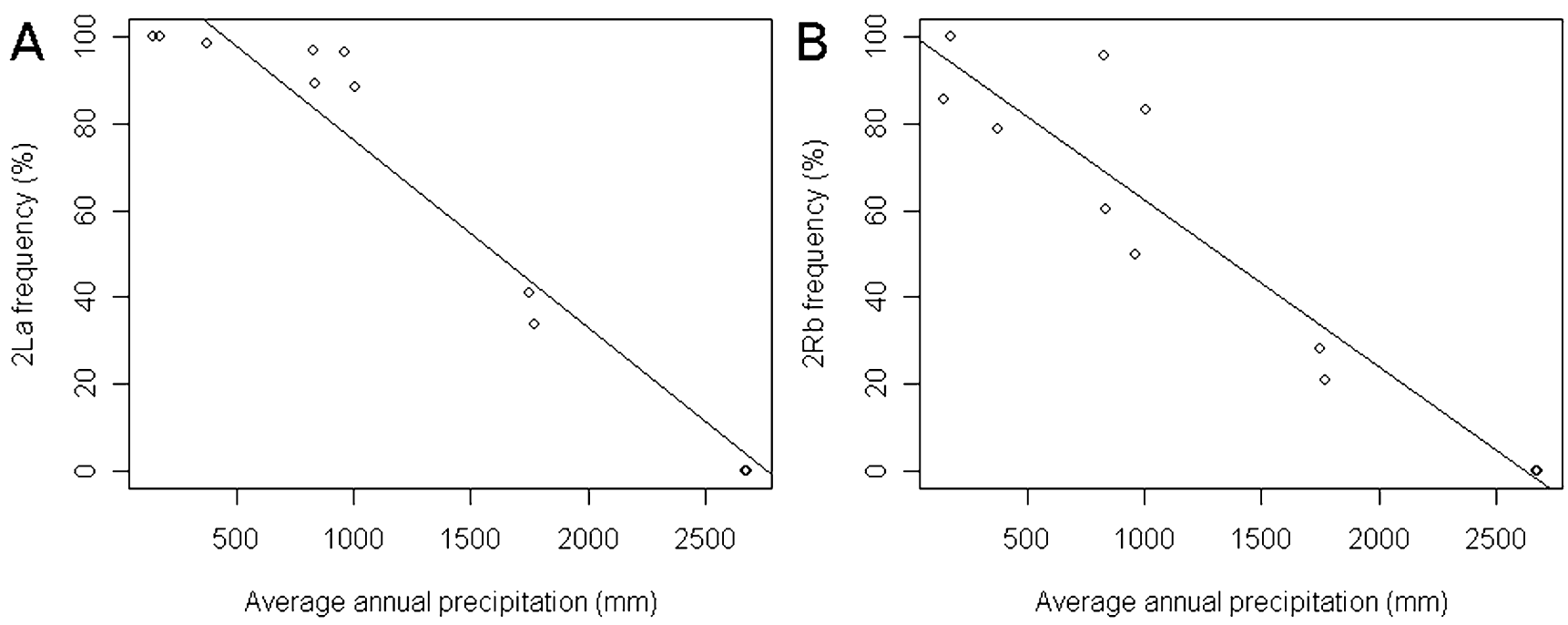

Figure 6

Precipitation and chromosome inversion. A: Inverse correlation between 2 La inversion frequency and average annual precipitation. Average annual precipitation was calculated as for the data represented in Figure 5. $\mathrm{m}=$ average annual precipitation for each site. Details of precipitation data are provided in Additional file I. The solid line is a linear model $(y \sim a x+b)$ of data with coefficients of $a=-0.0434 \pm 0.00395\left(P=1.65 \times 10^{-6}\right)$ and $b=120 \pm 5.85\left(P=7.39 \times 10^{-9}\right)$. B: Inverse correlation between $2 \mathrm{Rb}$ inversion frequency and annual precipitation. For a linear model, $a=-0.0385 \pm 0.0049 \mathrm{I}\left(\mathrm{P}=2.60 \times 10^{-5}\right)$ and $b=10 \mathrm{I} \pm$ $7.25\left(P=2.16 \times 10^{-7}\right)$.

Figure 4). The frequency of $2 \mathrm{La}$ and $2 \mathrm{Rb}$ in Godola were in line with the expectation based on precipitation. Genetic differentiation, based on microsatellite markers (Figure 2B and 2C), were also somewhat consistent with the association of land cover types and inversion polymorphism.

An unusual concentration of the 2Rd inversion in Godola resulted in the Bayesian analysis distinguishing it as a separate population (Figure 2A). Godola is located in an area surrounded by a mosaic of grasslands, permanent wetlands and croplands (Table 4). Permanent wetlands surround $19 \%$ of Godola, highest among our collection sites. A more detailed analysis of the effect of environmental parameters on the distribution of the $2 \mathrm{Rd}$ inversion will be necessary to gain an understanding of the relationship between the Godola-S form and other S forms.

The correlation between genetic markers and standard deviation of precipitation was also investigated. Areas with higher precipitation had greater variation in rainfall as well, as illustrated in Table 4. Thus the trend illustrated in Figures 5 and 6 remained the same between genetic markers and rainfall variation.

\section{Discussion}

Classification of populations of An. gambiae s.s. into chromosomal forms using four paracentric chromosome inversions (2Rb, c, $\mathrm{j}$ and $\mathrm{u}$ ) has been useful in identifying discrete sub-populations in Mali. Expanding this interpretation to include other areas in Africa has proven difficult because a significant proportion of karyotypes are ambiguous with respect to the classification scheme developed and used in Mali. Additional information, including molecular form, the 2La inversion and multi-locus microsatellite genotypes was employed in an attempt to obtain higher resolution of population structure in this species.

Seven groups were identified in the Bayesian analysis using molecular form, 2La, 2Rj, 2Rb, 2Rc, $2 \mathrm{Rd}$, and $2 \mathrm{Ru}$ inversion genotypes as markers (Figure 2A). These seven groups are Forest- $M$, Forest-S, Godola-S, Savanna-S, Bamako, Mopti-M bc/bc, and other Mopti-M forms (Figure $2 \mathrm{~A}$ ). Each group showed distinctive inversion polymorphism, and each occupied a different land cover type (Figure 1). Bayesian analysis using microsatellite data for the most part supported the analysis based on chromosome inversions and molecular form, with some notable exceptions (Figures $2 \mathrm{~B}$ and $2 \mathrm{C}$ ). The microsatellite analyses at $\mathrm{K}=4$ and $\mathrm{K}=5$ resolved groups with roughly equivalent likelihoods (Figure 3B). Microsatellites failed to resolve the Godola-S group within the range of $\mathrm{K}$ values $(\mathrm{K}=[1,8])$. At $\mathrm{K}=4$ the $\mathrm{S}$ form was divided into the Forest$\mathrm{S}$ form and all other $\mathrm{S}$ forms. At $\mathrm{K}=5$ the other $\mathrm{S}$ form group was split into the Bamako and Savanna forms. 


\section{The $M$ form}

The Bayesian analysis based on molecular form and karyotype divided $\mathrm{M}$ form populations into three discrete groups. The Forest $\mathrm{M}$ form was characterized as having the standard arrangement for all six major chromosomal inversions, namely $2 \mathrm{La}, 2 \mathrm{Rj}, 2 \mathrm{Rb}, 2 \mathrm{Rc}, 2 \mathrm{Rd}$ and $2 \mathrm{Ru}$. The Mopti-M form was further divided into two groups, one that is fixed for the $2 \mathrm{Rbc}$ inverted arrangement and the other $\mathrm{M}$ forms with the 2La/a genotype. The Forest-M form was the most distinct (Figures 2 and 4). The high degree of genetic divergence between the Forest- $M$ form and all the others was indicated not only by the $2 \mathrm{R}$ chromosome arrangement, but also at 20 microsatellite markers on the second and third chromosomes (Table 3, Figure 4 ). Moreover, the Forest-M form showed a strong association with very wet environments, distinguishing this form from the Mopti-M form, which is most abundant in much drier habitats (Figures 1 and 6, Table 4).

Despite occupying the same ecological zone and being identical with respect to karyotype (homosequential), the level of genetic differentiation $\left(\mathrm{F}_{\mathrm{ST}}=0.04263, \mathrm{P}=0.0000\right)$ between the Forest- $M$ and Forest-S forms was higher than among any of the other subspecific forms of An. gambiae s.s. (Table 3, Figure 4). The relationship between the Forest-M and Forest-S forms is clearly different from the relationship between the Mopti-M and Savanna-S forms in Mali. Hybridization between the Mopti-M and Savanna-S forms, although rare, has been frequently reported [8,3941], whereas reproductive isolation between sympatric Forest-M and S forms appears to be complete [14,15,35]. These results demonstrate that reproductive isolation, and not ecological barriers, plays the major role in limiting gene flow between the Forest $\mathrm{M}$ and $\mathrm{S}$ forms in Cameroon and between the Mopti-M and Savanna-S forms in Mali.

The $\mathrm{M}$ forms were further sub-divided into two groups based on the Bayesian analysis of karyotype data (Mopti$\mathrm{M}$ and "Other"-M, Figure 2A), while microsatellite data structured them as a single group (Figure $2 \mathrm{~B}$ and $2 \mathrm{C}$ ). The Mopti-M form is characterized as being fixed for the double homozygous b/c karyotype, whereas the "Other"-M form group carried the $2 \mathrm{Rb}$ and c inversions in other combinations or were standard karyotype. Both were fixed for the 2La inversion. Although genetic differentiation between the two groups as measured by pair-wise $\mathrm{F}_{\mathrm{ST}}$ is significant, the degree of divergence is relatively small and insufficient to classify them as two separate groups, that is as two distinct gene pools.

\section{The $S$ form}

The Bayesian clustering analysis based on molecular form and karyotype grouped $S$ form populations into four group: Forest-S, Godola-S, Savanna-S and Bamako-S (Figure $2 \mathrm{~A}$ ). The Forest-S group includes individuals with the standard (non-inverted) karyotype and individuals carrying the $2 \mathrm{La}$ and/or $2 \mathrm{Rb}$ inversions. Forest-S $2 \mathrm{Rb}$ heterozygotes were located in woody savanna habitats (Ndop and Foumbot), while only Forest-S form with standard arrangement were collected from evergreen forest habitats (Mutengene and Tiko). This distribution may reflect selection for the $2 \mathrm{Rb}$ inversion in drier habitats. $\mathrm{S}$ form $2 \mathrm{Rb}$ homozygotes were classified as Godola-S form if the 2Rd inversion is also present, Savanna-S form if no other inversions occur on chromosome $2 \mathrm{R}$, or Bamako-S if the $2 \mathrm{Rj}$, 2Rc and $2 \mathrm{Ru}$ inversions occur together.

The Bamako-S form was not resolved by the analysis based on microsatellites with $\mathrm{K}=4$, but was resolved at $\mathrm{K}$ $=5$. The Godola-S form however, was not resolved by the microsatellite data at either $K=4$ or $K=5$. The Godola-S group represents a distinctive group with respect to inversion polymorphism, notably a high frequency of the $2 \mathrm{Rd}$ inversion and $2 \mathrm{Rb}$ and $\mathrm{c}$ combinations not typically found in individuals within the $\mathrm{S}$ molecular form. However, the distinctive karyotypic polymorphism was not captured by the Bayesian analysis of microsatellite polymorphism.

Analysis of levels of genetic divergence, described with microsatellite-based $\mathrm{F}_{\mathrm{ST}}$ values (Table 3, Figure 4) suggest several relationships among the An. gambiae populations studied here. The major division distinguishes the Forest$\mathrm{M}$ form from all others (Figure 4). S form populations form four groups.

Interestingly, the Bamako-S and Savanna-S forms are the least diverged of the four, although it is the Bamako chromosomal form that has received the most attention, including the suggestion that it represents a distinct species $[37,42]$.

\section{Forces affecting the distribution of forms}

Recently Yawson et al. [16] reported higher levels of genetic divergence between within-form populations from different environments relative to between-form populations from the same environments in Ghana and Burkina Faso. This led them to conclude that barriers to gene flow among populations are due more to ecological barriers than reproductive isolation between molecular forms. The two sites in Cameroon from which we described the Forest-M form occur within a region that is more or less contiguous with the mangrove strand sites in southern Ghana from which Yawson et al. [16] collected $\mathrm{M}$ forms for their study [43]. Furthermore, the $1 \mathrm{~km}$ resolution land-cover map of Africa by Mayaux et al. [43] indicates that land-cover in northern Ghana is similar to southern Mali. These results suggest that the $\mathrm{M}$ form collected by Yawson et al. [16] in northern Ghana represent the Mopti- $M$ form while the $M$ form they collected in the 
mangrove strand of southern Ghana are of the Forest-M form. It is, therefore, likely that what Yawson et al. [16] describe as intra-form comparisons of $\mathrm{M}$ form populations are in fact inter-form comparisons between Forest-M and Mopti-M forms. Overall, the results suggest that reproductive isolation among forms plays an important role in restricting gene flow among populations. Evidence laid out here does, however, support the idea that ecological barriers also play a significant role.

The correlations between $2 \mathrm{La}$ and $2 \mathrm{Rb}$ inversion frequencies and precipitation (Figure 6) were significant. In this study, precipitation is used as a proxy for different habitat type, rather than the causal factor for the distribution of 2La and $2 \mathrm{Rb}$. Inversion polymorphisms in natural populations of An. gambiae s.s. are very complex and simple summary statistics, such as annual precipitation, are not sufficient to capture the diverse nature of the forces driving their distribution in nature. For example, the Godola collection has an unusual concentration of the 2Rd inversion which is difficult to explain by precipitation alone. Variation in rainfall was an obvious first environmental factor to consider, however describing this variable is not as trivial as it may seem. Rainfall is measured from 0 (meaning no rain) to some rain, and most of the regions included in this study have both rainy and dry seasons. Regions with high precipitation show greater variation in rainfall. Therefore, the correlation between genetic markers and the standard deviation of precipitation resulted in the same trend as the correlation with precipitation. Moreover, the standard deviation in rainfall is far greater than the mean (Table 4), illustrating the volatile nature of precipitation data. Examining the relationship between the distribution of genetic markers and rainfall in places like Tiko and Mutengene is further complicated because they have two rainy and two dry seasons. Other measures of rainfall variation, such as number of consecutive dry days or length of dry season can be explored. Development of summary statistics that may better reflect various rainfall patterns, as well as investigation of other environmental parameters are needed.

Microsatellites did detect population groups according to ecology and molecular forms. Division of Mopti-M, Savanna-S and Bamako-S groups are consistent with previous studies. Subdivision of the $M$ form into Mopti-M and Forest-M forms has strong support in all of the Bayesian analyses presented here, as was subdivision of the $S$ form into Savanna-S and Forest-S forms, although examination of Figures $2 \mathrm{~B}$ and $2 \mathrm{C}$ suggest that the latter division is less clear.

\section{Conclusion}

Overall this study confirms the Forest- $\mathrm{M}$ form as a distinct group, that lacks chromosome inversion polymorphism, is the most highly diverged of all the recognized subspecific forms of An. gambiae s.s. and is distinguished from other $\mathrm{M}$ molecular form populations by having a strong preference for environments with relatively high precipitation. The Forest-M form occurs in sympatry with the Forest- $\mathrm{S}$ form and reproductive isolation between the two appears to be complete, that is, no hybrids were observed. The relationship between the Forest- $M$ form and Mopti-M form is less clear. It is clear that the two are relatively highly diverged, $\mathrm{F}_{\mathrm{ST}}=0.02487$ compared for example to the level of divergence between the Bamako and Savanna chromosomal forms in Mali, $\mathrm{F}_{\mathrm{ST}}=0.00559$. However, we lack good information as to whether the Forest-M and Mopti-M forms are reproductively isolated since we have not identified sites at which the two are sympatric.

When investigating associations between genetic markers and important phenotypes such as insecticide resistance and malaria parasite refractory features, disregard of existing population structure may lead to identification of spurious associations or may obfuscate true associations. The level of genetic differentiation and geographic distribution of the Forest-M form illustrates the potential danger of relying solely on molecular form for genotype/phenotype association studies.

\section{Competing interests}

The authors declare that they have no competing interests.

\section{Authors' contributions}

YL designed and performed experiments, analysed data and drafted the manuscript. CRM, AF, RDM, AGA, and AJC performed cytogenetic analysis. EF, SFT, AF, AJC, and GCL collected mosquito specimens. GCL designed experiments, discussed the results and implications and drafted the manuscript. All authors commented on the manuscript at all stages.

\section{Additional material}

\section{Additional File 1}

Table S1. Geographic information for each collection sites and annual precipitation recorded in stations near the collection sites.

Click here for file

[http://www.biomedcentral.com/content/supplementary/14752875-8-75-S1.xls]

\section{Additional File 2}

Table S2. Karyotype and microsatellite genotype data of the mosquito samples used for this study. Also includes membership coefficients of $K=$ 7 clustering based on molecular form and karyotype and membership coefficients of $K=5$ clustering based on microsatellite.

Click here for file

[http://www.biomedcentral.com/content/supplementary/14752875-8-75-S2.xls] 


\section{Additional File 3}

Table S3. Abundance of $2 R b$ inversion in $M$ forms in Mali and $S$ forms in Cameroon.

Click here for file

[http://www.biomedcentral.com/content/supplementary/14752875-8-75-S3.xls]

\section{Acknowledgements}

We thank Dr. Yongkang Xue and Dr. Charles E. Taylor for the precipitation data. The research described in this paper was supported by a grant from the NIH to GCL (ROIAl40308).

\section{References}

I. Lehmann T, Licht M, Elissa N, Maega BT, Chimumbwa JM, Watsenga FT, Wondji CS, Simard F, Hawley WA: Population structure of Anopheles gambiae in Africa. J Hered 2003, 94: I33-I47.

2. Coluzzi M, Sabatini A, Petrarca V, Di Deco MA: Chromosomal differentiation and adaptation to human environments in the Anopheles gambiae complex. Trans R Soc Trop Med Hyg 1979, 73:483-497.

3. Touré YT, Petrarca V, Traoré SF, Coulibaly A, Maïga HM, Sankaré O Sow M, Di Deco MA, Coluzzi M: Ecological genetic studies in the chromosomal form Mopti of Anopheles gambiae s.str. in Mali, west Africa. Genetica 1994, 94:213-223.

4. Lanzaro GC, Touré YT, Carnahan J, Zheng L, Dolo G, Traoré S, Petrarca $\mathrm{V}$, Vernick KD, Taylor CE: Complexities in the genetic structure of Anopheles gambiae populations in west Africa as revealed by microsatellite DNA analysis. Proc Natl Acad Sci USA 1998, 95: |4260-14265.

5. Touré YT, Petrarca V, Traoré SF, Coulibaly A, Maïga HM, Sankaré O, Sow M, Di Deco MA, Coluzzi M: The distribution and inversion polymorphism of chromosomally recognized taxa of the Anopheles gambiae complex in Mali, West Africa. Parassitologia 1998, 40:477-51।.

6. Bayoh MN, Thomas CJ, Lindsay SW: Mapping distributions of chromosomal forms of Anopheles gambiae in West Africa using climate data. Med Vet Entomol 200I, I 5:267-274.

7. Wang-Sattler R, Blandin S, Ning Y, Blass C, Dolo G, Touré YT, della Torre A, Lanzaro GC, Steinmetz LM, Kafatos FC, Zheng L: Mosaic genome architecture of the Anopheles gambiae species complex. PLoS One 2007, 2:el249.

8. Tripet F, Touré YT, Taylor CE, Norris DE, Dolo G, Lanzaro GC DNA analysis of transferred sperm reveals significant levels of gene flow between molecular forms of Anopheles gambiae. Mol Ecol 2001, I0: 1725-1732.

9. Coluzzi M, Petrarca V, Di Deco MA: Chromosomal inversion intergradation and incipient speciation in Anopheles gambiae. Bollettino di Zoologia 1985, 52:45-63.

10. Fanello C, Santolamazza F, della Torre A: Simultaneous identification of species and molecular forms of the Anopheles gambiae complex by PCR-RFLP. Med Vet Entomol 2002, 1 6:46 I-464.

II. Favia G, della Torre A, Bagayoko M, Lanfrancotti A, Sagnon N'F, Touré YT, Coluzzi M: Molecular identification of sympatric chromosomal forms of Anopheles gambiae and further evidence of their reproductive isolation. Insect Mol Biol 1997, 6:377-383.

12. della Torre A, Fanello C, Akogbeto M, Dossou-yovo J, Favia G, Petrarca V, Coluzzi M: Molecular evidence of incipient speciation within Anopheles gambiae s.s. in West Africa. Insect Mol Biol 2001, 10:9-18.

13. Gentile G, Slotman M, Ketmaier V, Powell JR, Caccone A: Attempts to molecularly distinguish cryptic taxa in Anopheles gambiae s.s. Insect Mol Biol 200I, I 0:25-32.

14. Wondji C, Simard F, Fontenille D: Evidence for genetic differentiation between the molecular forms $M$ and $S$ within the Forest chromosomal form of Anopheles gambiae in an area of sympatry. Insect Mol Biol 2002, I I:I I-19.

15. Slotman MA, Tripet F, Cornel AJ, Meneses CR, Lee Y, Reimer LI Thiemann TC, Fondjo E, Fofana A, Traoré SF, Lanzaro GC: Evidence for subdivision within the $M$ molecular form of Anopheles gambiae. Mol Ecol 2007, 16:639-649.

16. Yawson AE, Weetman D, Wilson MD, Donnelly MJ: Ecological Zones Rather Than Molecular Forms Predict Genetic Differentiation in the Malaria Vector Anopheles gambiae s.s. in Ghana. Genetics 2007, I75:75I-76I.

17. Hunt RH: A cytological technique for the study of Anopheles gambiae complex. Parassitologia 1973, I5:137-139.

18. Scott JA, Brogdon WG, Collins FH: Identification of single specimens of the Anopheles gambiae complex by the polymerase chain reaction. Am J Trop Med Hyg 1993, 49:520-529.

19. Favia G, Lanfrancotti A, Spanos A, Sidén-Kiamos I, Louis C: Molecular characterization of ribosomal DNA polymorphisms discriminating among chromosomal forms of Anopheles gambiae s.s. Insect $\mathrm{Mol} \mathrm{Biol} 200 \mathrm{I}, 10: 19-23$.

20. Coluzzi M, Sabatini A, della Torre A, Di Deco MA, Petrarca V: A polytene chromosome analysis of the Anopheles gambiae species complex. Science 2002, 298:|4|5-14|8.

21. Zheng L, Benedict MQ, Cornel AJ, Collins FH, Kafatos FC: An integrated genetic map of the African human malaria vector mosquito, Anopheles gambiae. Genetics 1996, 143:941-952.

22. Moderate Resolution Imaging Spectroradiometer [http:// modis.gsfc.nasa.gov]

23. The Warehouse Inventory Search Tool [https:// wist.echo.nasa.gov/ wist/api/imswelcome/]

24. HEG (HDF-EOS to GeoTIFF convertersion Tool) [http:// newsroom.gsfc.nasa.gov/sdptoolkit/HEG/HEGHome.html]

25. Pritchard JK, Stephens M, Donnelly P: Inference of population structure using multilocus genotype data. Genetics 2000, I 55:949-959.

26. Falush D, Stephens M, Pritchard JK: Inference of population structure using multilocus genotype data: linked loci and correlated allele frequencies. Genetics 2003, I 64: I 567-I 587.

27. Falush D, Stephens M, Pritchard JK: Inference of population structure using multilocus genotype data: dominant markers and null alleles. Mol Ecol Notes 2007, 7:574-578.

28. Rosenberg NA: DISTRUCT: a program for the graphical display of population structure. Mol Ecol Notes 2003, 4: I37-I 38.

29. Excoffier L, Laval G, Balding D: Gametic phase estimation over large genomic regions using an adaptive window approach. Human Genomics 2003, I:7-19.

30. Excoffier L, Laval G, Schneider S: Arlequin ver. 3.0: An integrated software package for population genetics data analysis. Evol Bioinform Online 2005, I:47-50.

31. Guo SW, Thompson EA: Performing the exact test of HardyWeinberg proportion for multiple alleles. Biometrics 1992, 48:361-372.

32. Felsenstein J: PHYLIP - Phylogeny Inference Package (Version 3.2). Cladistics 1989, 5: I64-166.

33. Felsenstein J: PHYLIP (Phylogeny Inference Package) version 3.2. Department of Genome Sciences, University of Washington; 2005.

34. The R Project for Statistical Computing [http://www.rproject.org/index.html]

35. Wondji C, Simard F, Petrarca V, Etang J, Santolamazza F, della Torre A, Fontenille D: Species and Populations of the Anopheles gambiae complex in Cameroon with special emphasis on chromosomal and molecular forms of Anopheles gambiae s.s. Med Entomol 2005, 42:998-1005.

36. Touré $Y$, Petrarca V, Coluzzi M: Nuove entitá del complesso Anopheles gambiae in Mali. Parassitologia 1983, 25:367-370.

37. Manoukis NC, Powell JR, Touré MB, Sacko A, Edillo FE, Coulibaly MB, Traoré SF, Taylor CE, Besansky NJ: A test of the chromosomal theory of ecotypic speciation in Anopheles gambiae. Proc Natl Acad Sci USA 2008, I 05:2940-2945

38. Coluzzi M: Malaria Vector Analysis and Control. Parasitology Today 1992, 8: II3-II8.

39. Taylor C, Touré YT, Carnahan J, Norris DE, Dolo G, Traoré SF, Edillo FE, Lanzaro GC: Gene flow among populations of the malaria vector, Anopheles gambiae, in Mali, West Africa. Genetics 200I, I 57:743-750.

40. Tripet F, Dolo G, Lanzaro GC: Multilevel analyses of genetic differentiation in Anopheles gambiae s.s. reveal patterns of gene flow important for malaria-fighting mosquito projects. Genetics 2005, 169:313-324. 
4I. Weill M, Chandre F, Brengues C, Manguin S, Akogbeto M, Pasteur N, Guillet P, Raymond M: The kdr mutation occurs in the Mopti form of Anopheles gambiae s.s. through introgression. Insect Mol Biol 2000, 9:45I-455.

42. Powell JR, Petrarca V, della Torre A, Coccone A, Coluzzi M: Population Structure, Speciation, and Introgression in the Anopheles gambiae Complex. Parassitologia 1999, 4I: I0 I-I I3.

43. Mayaux $P$, Bartholomé E, Fritz S, Belward A: A new land-cover map of Africa for the year 2000. J Biogeography 2004, 31:86I-877.

Publish with Bio Med Central and every scientist can read your work free of charge

"BioMed Central will be the most significant development for disseminating the results of biomedical research in our lifetime. " Sir Paul Nurse, Cancer Research UK

Your research papers will be:

- available free of charge to the entire biomedical community

- peer reviewed and published immediately upon acceptance

- cited in PubMed and archived on PubMed Central

- yours - you keep the copyright

Submit your manuscript here:

http://www.biomedcentral.com/info/publishing_adv.asp
BioMedcentral 